\title{
Enhanced Antioxidant Activity of Nano-Selenium Produced Using a Bacterial Isolate Citrobacter sp.
}

\author{
Awanish Kumar ${ }^{1(D)}$, Bablu Prasad ${ }^{2}$ (D) , Deepak Singh ${ }^{3}$, Kumar Suranjit Prasad 1,* (D) \\ 1 Centre of Environmental Science, Institute of Interdisciplinary Studies, University of Allahabad (A Central University), \\ Prayagraj, Uttar Pradesh- 211002, India; akawanish43@gmail.com (A.K.); \\ 2 Department of Environmental Studies, Faculty of Science, The Maharaja Sayajirao University of Baroda, Vadodara, \\ Gujarat- 390002, India; akashganga812@gmail.com (B.P.); \\ 3 Department of Environmental Studies, Deshbandhu College, University of Delhi, New Delhi 110019; \\ deepaksingh1947@gmail.com (D.S.); \\ * Correspondence: ksuranjit@allduniv.ac.in (K.S.P.);
}

Received: 9.07.2021; Revised: 15.09.2021; Accepted: 20.09.2021; Published: 4.11.2021

\begin{abstract}
Selenium is essential for human, plant, and animal growth and reproduction. Because of their biological activity, bioavailability, and low toxicity, selenium nanoparticles are regarded as a promising material for many applications in biomedicine and health. Selenium-resistant bacteria were isolated from garden soil and identified as Citrobacter amalonaticus strain ARB01. TEM, UV-visible spectrophotometer, FTIR, and EDAX were used to characterize biosynthesized SeNPs using the cellfree extract of ARB01. The antioxidant activity of biologically functionalized SeNPs was evaluated using the 1,1-diphenyl-2-picrylhydrazyl (DPPH), ferric reducing antioxidant strength (FRAP), and 2, 2'-azinobis (3-ethylbenzothiazoline-6-sulfonic acid) (ABTS) assays. The Dot-blot test was used to perform a qualitative study of the antioxidant activity of SeNPs using the TLC-DPPH technique. The TEM analysis revealed spherical SeNPs with diameters ranging from $50 \mathrm{~nm}$ to $80 \mathrm{~nm}$. Because of the synergistic effect of biomolecules involved in nanoparticle synthesis, SeNPs showed higher antioxidant activity. This study reveals that the antioxidant activity of nanoparticles increased due to functionalization by biomolecules present in the cell-free extract of bacterial isolate.
\end{abstract}

Keywords: nanoparticles; selenium; Citrobacter amalonaticus; antioxidant

(C) 2021 by the authors. This article is an open-access article distributed under the terms and conditions of the Creative Commons Attribution (CC BY) license (https://creativecommons.org/licenses/by/4.0/).

\section{Introduction}

In recent years, nanotechnology has taken a significant role in scientific research fields like health, nutrition, medicine, and progress in physics, chemistry, and biology[1,2]. Nanoscale particles have distinct optoelectronic, magnetic, and mechanical properties that distinguish them from bulk materials [3-5]. Because of their small size and chemistry, nanoparticles have a wide range of applications [6,7]. Selenium (Se) is a naturally occurring metalloid element in the environment. Selenium resources are limited and non-renewable [8]. Selenium is a multifunctional material with unique physical properties such as high optical conductivity, anisotropy of thermal conductivity, and X-ray sensing responses. Nanoparticles have distinct properties due to their greater surface/volume ratio and higher surface energy [9]. Selenium nanoparticles have a broad range of applications in chemistry, physics, biology, biomedical, pharmaceutical, and material sciences [10]. The biological approach for the synthesis of nanoparticles has sparked the interest of researchers because it is both eco-friendly and cost-effective, as reported by many studies [11-13]. Ion-sputtering solvothermal 
procedure, sol-gel technique, ultraviolet irradiation, laser ablation, Riley oxidation, and ultrasonic treatment are examples of physical and chemical methods. Microwave irradiation was used to synthesize hexagonal selenium nanoparticles using selenium tetrachloride as a precursor and hydrazine as a reducing agent [14]. A simple wet chemical method was used to synthesize spherical SeNPs with a 76-150 nm size range by reducing selenosulphate with an ionic liquid [15]. Nanoparticles of different sizes and shapes have been synthesized using biological reducing agents with varying bioactivity [16-18]. Staphylococcus aureus, a Gram +ve bacteria, was used to synthesize small-sized selenium nanoparticles [19]. Lactobacillus acidophilus, a probiotic bacteria, was used to synthesize non-toxic selenium nanoparticles [20]. Selenium is important for human health because it regulates many oxidation and reduction processes through seleno-enzymes and selenoproteins. During the metabolic process, free radicals and reactive oxygen species are formed, which cause oxidative stress and cellular damage. Antioxidants are molecules that act as reducing agents by donating electrons to free radicals to stabilize them. Antioxidants protect DNA, cell, and organ systems from free radical damage. Antioxidant substances like vitamins, enzymes, flavonoids, and polyphenols are abundantly found in plants, fruits, vegetables, and some naturally derived products [21]. Synthesized selenium nanoparticle shows antimicrobial [22,23], antioxidant [24], antidiabetic $[25,26]$, and cytotoxic activity [27-29].

\section{Materials and Methods}

This study synthesized SeNPs using a cell-free extract of the strain ARB01, a biological reducing agent, followed by physical characterization and evaluating their qualitative and quantitative antioxidant activity. During the experiment, analytical grade chemicals obtained from Merck (India) were used.

\subsection{Isolation of selenium resistant bacteria.}

The soil sample was collected and dissolved in a $0.9 \%$ saline solution. In a flask,50 $\mathrm{ml}$ of nutrient broth media containing $500 \mu \mathrm{mol} / \mathrm{L} \mathrm{Na}_{2} \mathrm{SeO}_{3}$ was taken and inoculated with $1 \mathrm{ml}$ of the prepared soil solution. In brief, the approach was followed as per the previously published study[24]. Red colonies of selenium-resistant bacteria appeared on the culture plates after incubation (Figure 1).

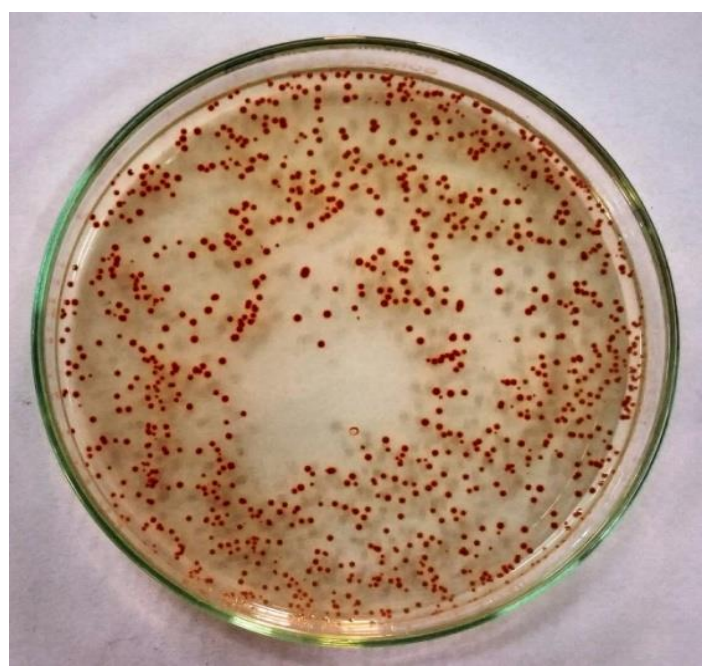

Figure 1. The growth of selenium-resistant bacteria onto nutrient agar plate supplemented with sodium selenite, reduction of selenite ions is evident by the presence of red bacterial colonies. 
2.2. Genomic DNA isolation, agarose gel electrophoresis, PCR, and analysis of nucleotide sequences.

The methods employed for isolation of DNA, agarose gel electrophoresis, PCR, and sequence analysis were followed according to the earlier study [24].

\subsection{Preparation of cell-free extract and synthesis of selenium nanoparticles.}

The cell-free extract of Citrobacter amalonaticus strain ARB01 was prepared, and SeNPs were synthesized by following the experimental procedure published previously [24].

\subsection{Physical characterization of synthesized selenium nanoparticles.}

Physical characterization of SeNPs was done by using UV-visible spectroscopy, Transmission electron microscopy, Fourier-transform infrared (FTIR) spectroscopy, and Energy-dispersive X-ray spectroscopy (EDAX) [24].

\subsection{Assay for evaluation of the antioxidant activity of SeNPs.}

The antioxidant activity of synthesized selenium nanoparticles was evaluated using the TLC-DPPH assay (for qualitative analysis), DDPH, ABTS, and FRAP assay (for quantitative analysis).

\subsubsection{DPPH assay.}

The 1,1-diphenyl-2- picrylhydrazyl (DPPH) assay was done according to the procedure described by Kumar et al.[24]. The qualitative analysis for the antioxidant activity of SeNPs was carried out by a Dot-blot test using the TLC-DPPH assay adapted from the study by Cieśla et al. [30] with some technical modification. Spraying was done on the TLC plate (silica plate) with a $0.2 \%$ methanolic DPPH solution instead of immersing the TLC plate. All the samples were prepared at a concentration of $2 \mu \mathrm{g} / \mathrm{ml}$. The antioxidant activity of DPPH was calculated as \% inhibition of DPPH by Eq.1.

$\%$ inhibition of DPPH radicals $=\frac{(\text { Absorbance blank-Absorbance })}{\text { Absorbance blank }} \times 100 \quad$ Equation 1

\subsubsection{ABTS assay.}

In brief, the experimental procedure for the 2, 2'-azinobis (3-ethylbenzothiazoline-6sulfonic acid) (ABTS) assay was followed according to the method described [24]. The percent inhibition of $\mathrm{ABTS}^{\circ}+$ radicals was determined by the Eq. 2

$\%$ inhibition of $A B T S^{\circ}+$ radicals $=\frac{(\text { Absorbance blank-Absorbance })}{\text { Absorbance blank }} \times 100 \quad$ Equation 2

\subsubsection{FRAP assay.}

Ferric reducing antioxidant power (FRAP) assay is a widely used method. In this method, antioxidant materials are used for the reduction of colorless ferric tripyridyltriazine $\left(\mathrm{Fe}^{3+}\right.$ TPTZ) complex into a colored ferrous tripyridyltriazine $\left(\mathrm{Fe}^{2+} \mathrm{TPTZ}\right)$ complex at low $\mathrm{pH}$ [31]. The experimental work for the FRAP assay was carried out according to the procedure previously published [24]. 


\section{Results and Discussion}

\subsection{Identification of selenium resistant bacterial isolate.}

Citrobacter amalonaticus strain ARB01 was isolated as selenium-resistant bacteria from soil (Figure2). The phylogenetic study of the bacterial isolate Citrobacter amalonaticus strain ARB01 revealed similar homology towards Citrobacter amalonaticus strain CECT883. It was found to be distantly related to Citrobacter gillenii strain CDC4693-86. A dendrogram was constructed to determine ARB01's phylogenetic relationship to other Citrobacter species.

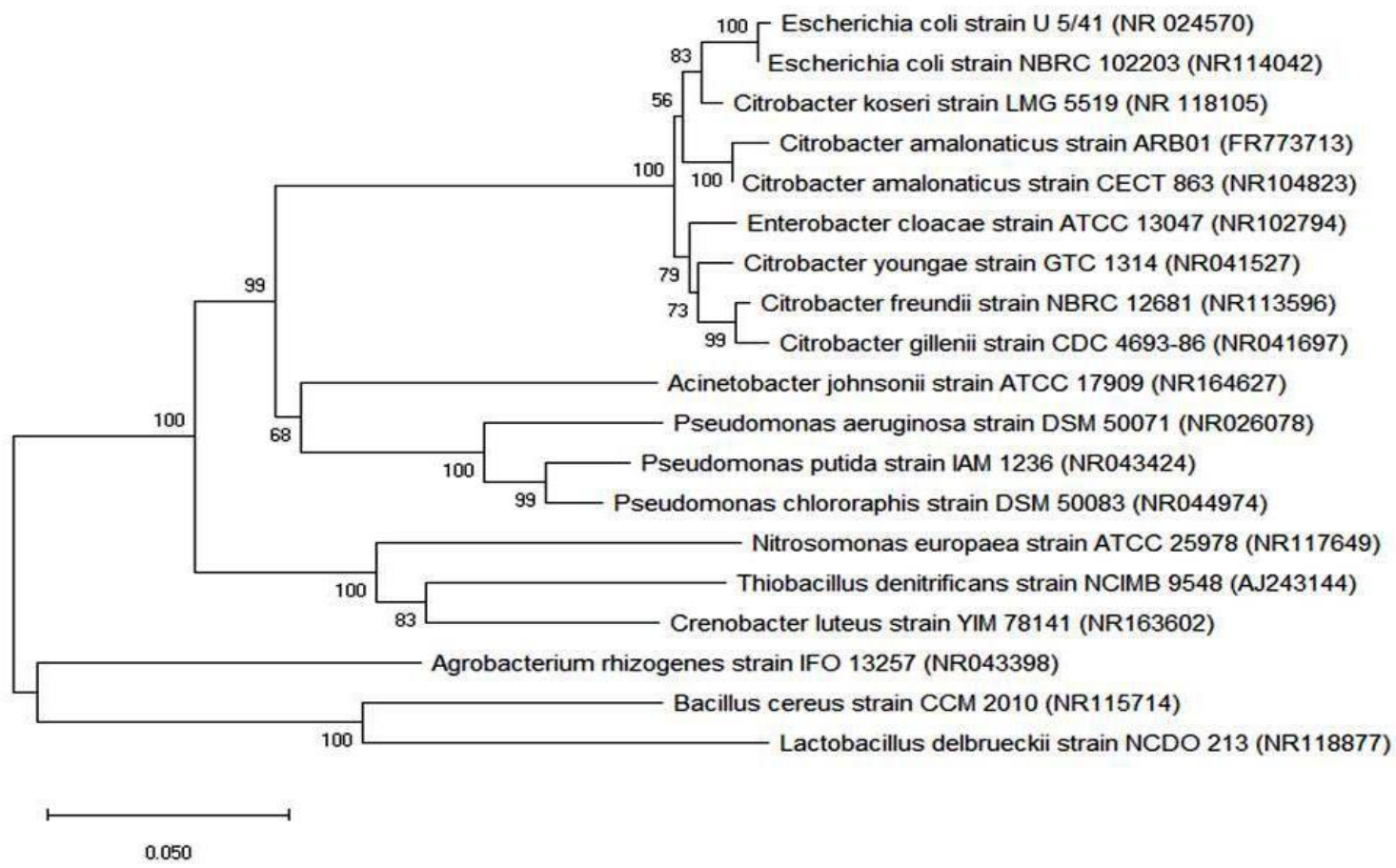

Figure 2. The phylogenetic tree depicts the evolutionary relationships of Citrobacter amalonaticus ARB01 with other members of their family at the bootstrap value of 1000 .

\subsection{UV-visible spectroscopy.}

The cell-free extract was used to synthesize selenium nanoparticles. The UV-visible absorption spectrum shows absorption maxima at $360 \mathrm{~nm}$ (Figure 3). The absorbance spectra of selenium nanoparticles synthesized from cell-free extract Citrobacter amalonaticus strain ARB01 were observed in the wavelength range of $250 \mathrm{~nm}$ to $700 \mathrm{~nm}$ (Figure 3).



Figure 3. After 48 hours of incubation, the UV-Visible absorption spectrum shows absorption maxima at 360 $\mathrm{nm}$, and a red-colored colloidal solution formed due to the formation of SeNPs.

There were no noticeable absorbance maxima in the zero-hour spectrums. After 48 hours, the absorbance increased significantly, with a maximum absorbance at $360 \mathrm{~nm}$. 
According to Ingole et al., the absorbance maxima of synthesized nanoparticles have been at $300 \mathrm{~nm}$ [32]. Prasad and Selvaraj recorded the absorption maxima of SeNPs at $390 \mathrm{~nm}$ as well [33]. As a result, particle size is responsible for forming absorption maxima at $360 \mathrm{~nm}$, which is consistent with the previous studies, supporting the formation of selenium nanoparticles. The molecules involved in the synthesis of selenium nanoparticles cause differences in absorption maxima.

\subsection{Transmission electron microscopy of SeNPs.}

According to the TEM study, the synthesized nanomaterial is spherical with a diameter of 50-80 nm (Figure 4). Research reveals that selenium nanoparticles formed by the bacterium Bacillus subtilis ranged in size from $50 \mathrm{~nm}$ to $400 \mathrm{~nm}$ [34]. Similarly, in another study, the diameter of biosynthesized SeNPs was found to be in the 20-80 $\mathrm{nm}$ range [35]. In addition, biomimetic spherical SeNPs with diameters ranging from 30 to $150 \mathrm{~nm}$ have been reported [3]. The obtained results were consistent with earlier published studies. The size of the synthesized nanomaterial is determined by the concentration of the precursor material, the reducing agent, and the reaction time. The crystalline nature of the synthesized selenium nanoparticles was confirmed by the selected area electron diffraction (SAED) pattern.

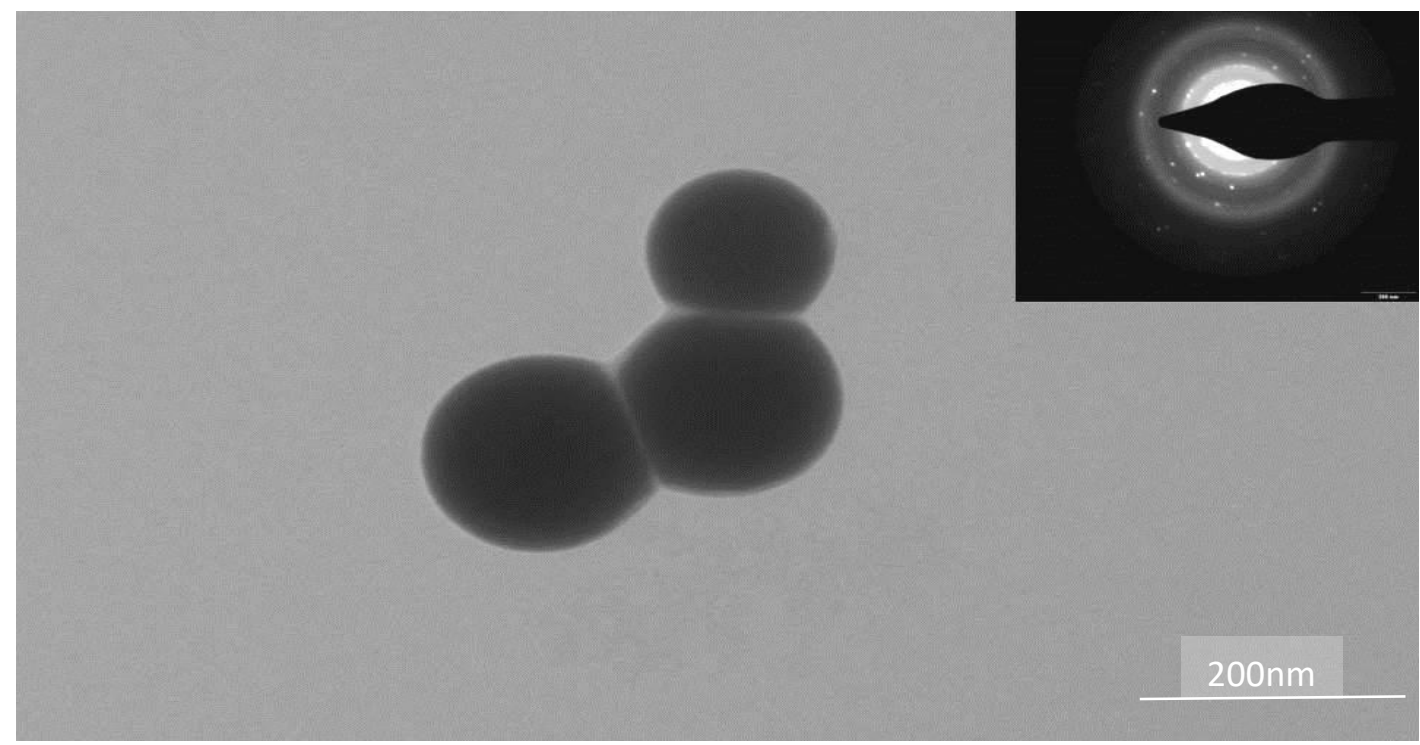

Figure 4. TEM image showing the spherical SeNPs of 50-80 nm size along with SAED pattern confirming the crystalline nature of selenium nanoparticle.

\subsection{Fourier transform infrared spectroscopy.}

The Fourier transform infrared (FTIR) spectroscopy generates spectra based on the biological compounds' absorbance of infrared radiation (lipids, proteins, and polysaccharides). The intensity can be plotted at each wavenumber as a percentage of light transmittance or absorbance [36-38]. The FTIR spectra of SeNPs synthesized using cell-free extract revealed bands associated with various biological compounds such as proteins, polysaccharides, and lipids. Figures 5 (a) and (b) display a comparison of the FTIR spectra of the control sample (cell-free medium) and the test sample (Bio-SeNPs). The spectral picture represents the number of absorption bands induced by molecular vibrations of various functional groups. One peak between 3400 and $3200 \mathrm{~cm}-1$ can be defined as the absorption peak of the NH stretching vibration or the $\mathrm{OH}$ stretching vibration of the H-bonded biomolecules. Weak bands found between 3000 and $2800 \mathrm{~cm}-1$ can be attributed to $\mathrm{CH}$ stretching vibrations of aliphatic side 
chains in organic molecules caused by symmetric and asymmetric stretching vibrations of methyl and methylene groups. A very weak band at around $2090 \mathrm{~cm}^{-1}$ can be attributed to the stretching vibration of the $\mathrm{C} \equiv \mathrm{C}$ bond. The absorption bands at around $1654-1634 \mathrm{~cm}^{-1}$ can be attributed to amide I of proteins involved in the capping of selenite ions. The spectral band at $1548 \mathrm{~cm}^{-1}$ and $1539 \mathrm{~cm}^{-1}$ can be assigned to the amide II of the proteins. The weaker band around $1410-1380 \mathrm{~cm}^{-1}$ can be assigned to the carboxylic group. The band at 1462 in the test sample (Figure $5 \mathrm{~b}$ ) can be assigned to scissoring vibrations of the methylene group of aliphatic side chains of biomolecules involved in the formation of SeNPs. The spectral bands around $1200-1000 \mathrm{~cm}^{-1}$ can be attributed to the various $\mathrm{C}-\mathrm{O}, \mathrm{C}-\mathrm{C}, \mathrm{C}-\mathrm{O}-\mathrm{H}$, or $\mathrm{C}-\mathrm{O}-\mathrm{C}$ vibrations in biomolecules (proteins and polysaccharides) [36,37]. The absorption peaks around 1000- 700 $\mathrm{cm}^{-1}$ may be due to the $\mathrm{C}-\mathrm{H}$ bending of aliphatic side chains in proteins and polysaccharides. The spectral band at $620 \mathrm{~cm}^{-1}$ can be assigned to $\mathrm{S}-\mathrm{S}$ stretching vibration.

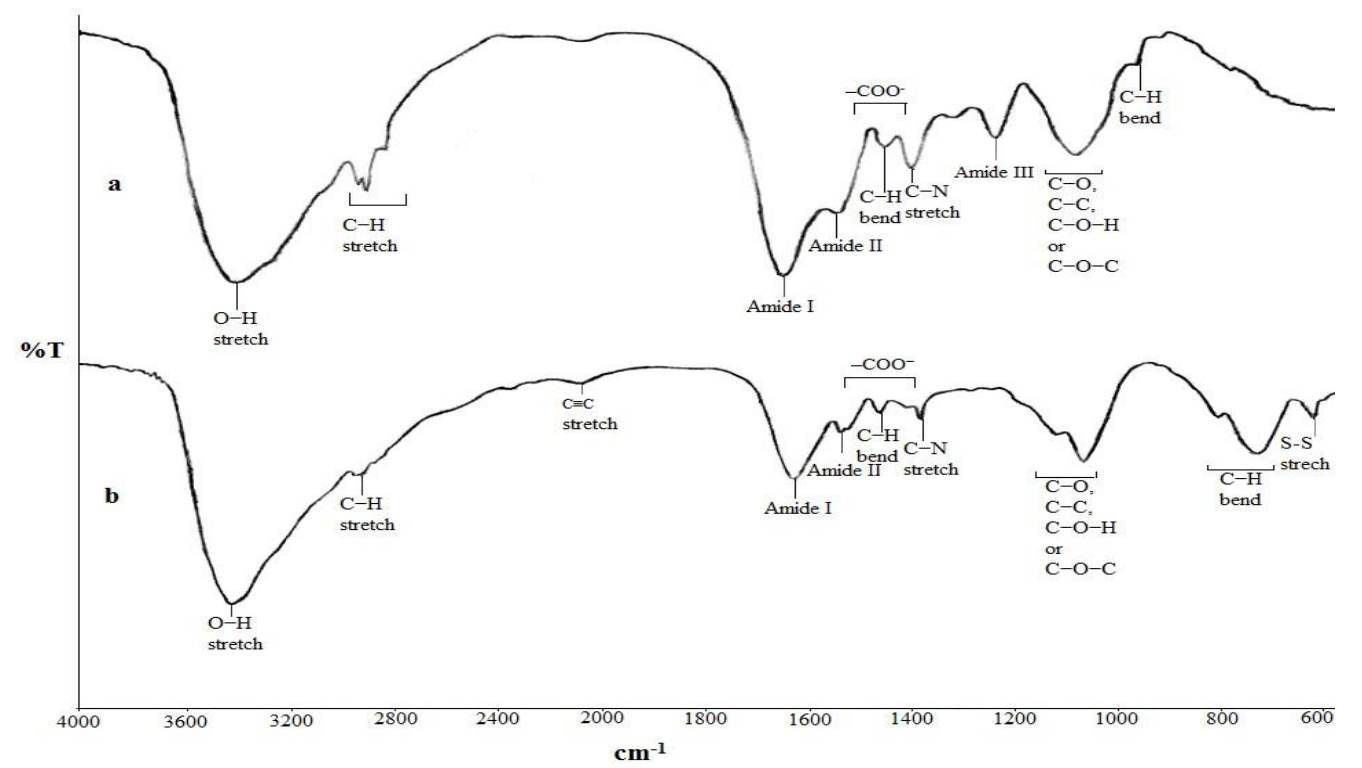

Figure 5. FTIR spectrums of (a) control and (b) biological samples containing SeNPs show the functional groups involved in nanoparticle synthesis.

\subsection{Energy-dispersive $X$-ray analysis (EDAX).}

The qualitative and quantitative status of elements present with the synthesized selenium nanoparticles is determined by energy-dispersive X-ray analysis. The EDAX study indicated a higher amount of selenium, as well as oxygen, carbon, and sodium (Figure 6) $[39,40]$.

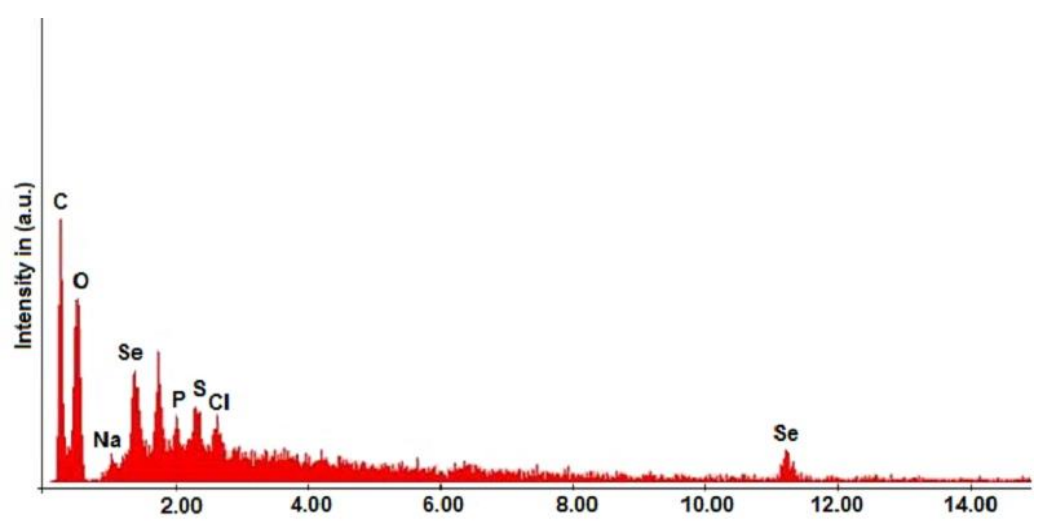

Figure 6. EDAX spectrum of synthesized nanomaterial showing the quantity of selenium along with other elements. 
The study showed a higher concentration of selenite (55\%) in nanoparticles, followed by carbon $(40 \%)$, oxygen $(18 \%)$, and sodium $(1.18 \%)$. These elements are present in biosynthesized nanomaterials because biomolecules are involved in the functionalization and stabilization of SeNPs.

\subsection{Antioxidant activity.}

The qualitativeTLC-DPPH assay revealed that SeNPs have antioxidant activity due to the synergistic effect of the biomolecules involved in nanoparticle synthesis. The antioxidant activity of selenium nanoparticles was demonstrated by the DPPH, ABTS, and FRAP assays (quantitative) (Figure 7). The antioxidant activity of synthesized SeNPs was evaluated by employing DPPH, ABTS, and FRAP assay [41-43]. The assay showed that selenium nanoparticles synthesized using the cell-free extract of Citrobacter amalonaticus strain ARB01 have antioxidant activity, which is higher than the cell-free extract and sodium selenite due to the synergistic effect of capping and stabilizing molecules. Above mentioned assays were done to evaluate the antioxidant activity of selenium nanoparticles, sodium selenite, the cell-free extract of ARB01, and ascorbic acid. After performing DPPH and ABTS assay, antioxidant activity was calculated by \% inhibition of DPPH and ABTS radicals.
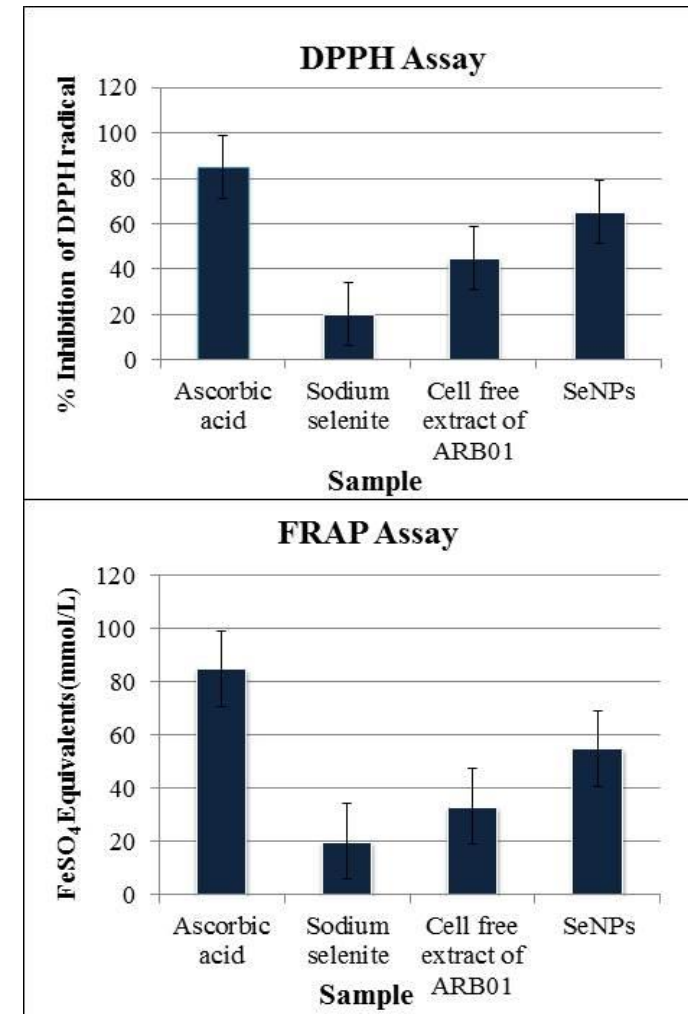

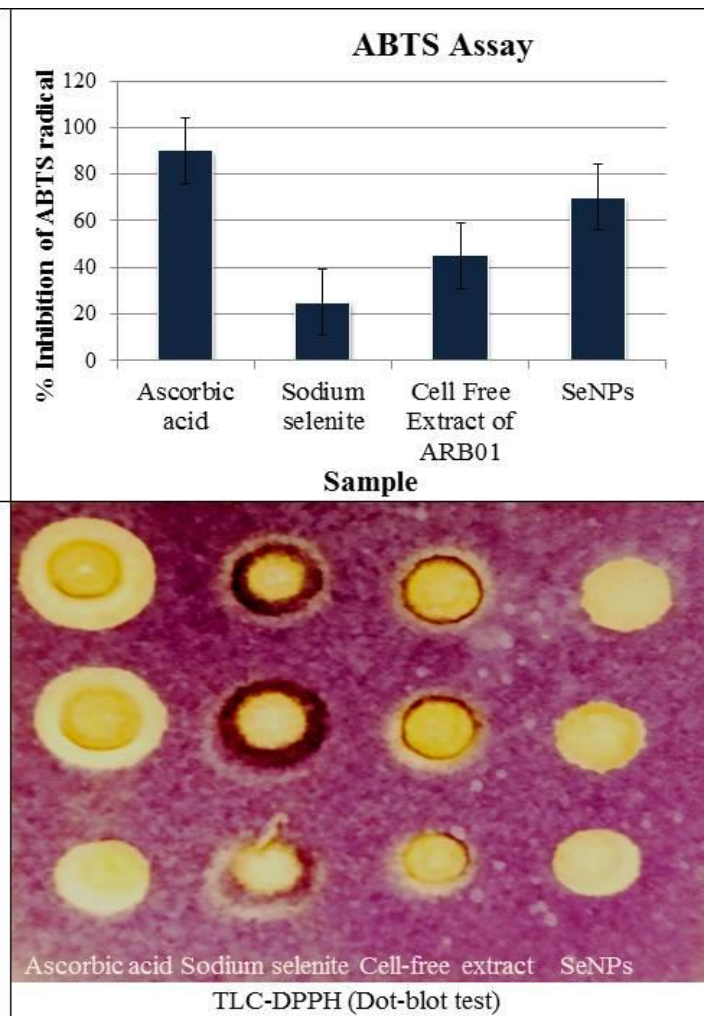

Figure 7. The antioxidant activity of SeNPs is higher in comparison to other samples, as presented in the form of a graphical figure.

The Dot-blot test was performed using the TLC-DPPH assay for the qualitative evaluation of the antioxidant activity. Decolourization occurred at the spot applied on the TLC plate after spraying the DPPH solution due to scavenging activity. The DPPH assay shows that

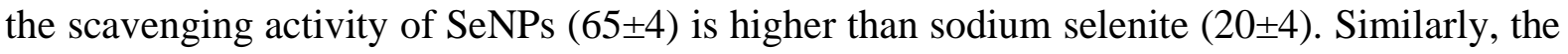
ABTS assay shows that the scavenging activity of SeNPs (70 \pm 3$)$ is higher than sodium selenite $(25 \pm 2)$. FRAP results were shown as $\mathrm{FeSO}_{4}$ equivalents in $\mathrm{mmol} / \mathrm{L}$. The result was shown in the form of mean $\pm \mathrm{SE}$ of the mean $(n=6)$ using statistical calculations at $5 \%$ of significance level (Figure 7). The FRAP assay showed higher antioxidant activity of selenium nanoparticles 
than sodium selenite ( $55 \pm 3$ and $20 \pm 2$ ), respectively. The antioxidant activity of the SeNPs is higher due to the synergistic effect of biomolecules involved in nanoparticle synthesis.

\section{Conclusions}

In this present study, a cell-free extract of bacterial isolate Citrobacter amalonaticus strain ARB01 was used to synthesize selenium nanoparticles. The cell-free extract contains biomolecules like proteins, lipids, and polysaccharides, which were involved in the formation of SeNPs. The TEM analysis showed spherical selenium nanoparticles with a size range of 50 $\mathrm{nm}$ to $80 \mathrm{~nm}$ diameters. For the first time, the antioxidant activity was evaluated qualitatively by using the TLC-DPPH assay and quantitatively by DPPH, ABTS, and FRAP assay. The DPPH, FRAP, and ABTS assay manifested that selenium nanoparticles have enhanced antioxidant activity than sodium selenite and cell-free extract. The increase in the antioxidant activity of SeNPs was due to the synergistic effect of biomolecules involved in the functionalization of the nanomaterial. Besides, extensive investigation of SeNPs is needed for biomedical and pharmaceutical applications due to cytotoxic, antimicrobial, and antidiabetic activity.

\section{Funding}

This research received no external funding.

\section{Acknowledgments}

KSP would like to acknowledge the help rendered by the Sophisticated Instrumentation Centre for Applied Research and Testing (SICART), Anand, Gujarat, India.

\section{Conflicts of Interest}

The authors declare no conflict of interest.

\section{References}

1. Bayda, S.; M. Adeel, M.; Tuccinardi, T.; Cordani, M.; Rizzolio, F. The history of nanoscience and nanotechnology: From chemical-physical applications to nanomedicine. Molecules2020, 25, 112,https://doi.org/10.3390/molecules25010112.

2. Ndlovu, N.;Mayaya, T.; Muitire, C.; Munyengwa, N. Nanotechnology applications in crop production and food systems.Int. J. Plant Breed. Crop Sci2020, 7, 624-634.

3. Prasad, K.S.; Vyas, P.; Prajapati, V.; Patel, P.; Selvaraj, K. Biometric synthesis of selenium nanoparticles using cell-free extract of Microbacterium sp. ARB05. Micro Nano Lett2012, 7, 1-4, https://doi.org/10.1049/mnl.2011.0498.

4. Mino, L.; Agostini, G.; Borfecchia, E.; Pearce, C.I.; Coker,V.S.; Charnock, J.M.; Pattrick,R.A.D.; Mosselmans, J.F.W.; Law, N.; Beveridge, T.J.; Lloyd, J.R. Microbialmanufacture of chalcogenide-based nanoparticles via the reduction of selenite usingVeillonella atypica: An in situ EXAFS study. Nanotechnology2008, 19, 13,https://doi.org/10.1088/0957-4484/19/15/155603.

5. Jacob, J.M.; Lens, P.N.L.; Mohan, R. Microbial synthesis of chalcogenide semiconductornanoparticles : A review. Microb Biotechnol2016, 9, 11-21,https://doi.org/10.1111/1751-7915.12297.

6. Khan, I.; Saeed, K.; Khan, I. Nanoparticles: Properties, applications, and toxicities. Arab JChem2019, 12 , 908-931, https://doi.org/10.1016/j.arabjc.2017.05.011.

7. Shi, X.D.; Tian, Y.Q.; Wu, J.L.; Wang, S.Y. Synthesis, characterization, and biological activity of selenium nanoparticles conjugated with polysaccharides.Crit Rev Food Sci Nutr2020, 61, 22252236,https://doi.org/10.1080/10408398.2020.1774497.

8. El-Ramady, H.; Abdalla, N.; Taha, H.; Dirk, S.; Silvia, H.; El-Henawy, A. Selenium, andnano-selenium in plant nutrition. Environ Chem Lett2016, 14, 123-147,https://doi.org/10.1007/s10311-015-0535-1.

9. Ansari, S.A.; Husain, Q. Potential applications of enzymes immobilized on/in nanomaterials : A review. 
Biotechnol Adv2012, 30, 512-523,https://doi.org/10.1016/j.biotechadv.2011.09.005.

10. Kumar, A.; Prasad, K.S. Role of nano-selenium in health and environment. J. Biotechnol2021, 325, 152-163, https://doi.org/10.1016/j.jbiotec.2020.11.004.

11. Prasad, K.S.; Pathak, D.; Patel, A.; Dalwadi, P.; Prasad, R.; Patel, P.; Selvaraj, K.Biogenic synthesis of silver nanoparticles using Nicotiana tobaccum leaf extract andstudy of their antibacterial effect. African $J$ Biotechnol2011, 10, 8122-8130,https://doi.org/10.5897/ajb11.394.

12. Alvi, G.B.; Iqbal, M.S.;Ghaith, M.M.S.; Haseeb, A.; Ahmed, B.; Qadir, M.I. Biogenic selenium nanoparticles (SeNPs) from citrus fruit have anti-bacterial activities. SciRep2021, 11, 4811,https://doi.org/10.1038/s41598021-84099-8.

13. Abu-Elghait, M.; Hasanin, M.; Hashem, A.H.; Salem, S.S. Ecofriendly novel synthesis of tertiary composite based on cellulose and myco-synthesized selenium nanoparticles: characterization, antibiofilm, and biocompatibility. IntJ Biol Macromol2021, 175, 294-303, https://doi.org/10.1016/j.ijbiomac.2021.02.040.

14. Panahi-Kalamuei, M.; Salavati-Niasari, M.; Hosseinpour-Mashkani, S.M. Facilemicrowave synthesis, characterization, and solar cell application of seleniumnanoparticles. J Alloys Compd2014, 617, 627632,https://doi.org/10.1016/j.jallcom.2014.07.174.

15. Langi, B.; Shah, C.; Singh, K.; Chaskar, A.; Kumar, M.; Bajaj, P.N. Ionic liquid-inducedsynthesis of selenium nanoparticles. Mater Res Bull2010, 45, 668-671,https://doi.org/10.1016/j.materresbull.2010.03.005.

16. Fan, D.; Li, L.; Li, Z.; Zhang, Y.; Ma, X; Wu, L.; Zhang, H.; Guo, F. Biosynthesis of selenium nanoparticles and their protective, antioxidative effects in streptozotocin-induced diabetic rats.SciTechnolAdvMater 2020, 21, 505-514,https://doi.org/10.1080/14686996.2020.1788907.

17. Borah, S.N.; Goswami, L.; Sen, S.; Sachan, D.; Sarma, H.; Montes, M.;Peralta-Videa, J.R.; Pakshirajan, K.; Narayan, M. Selenite bioreduction and biosynthesis of selenium nanoparticles by Bacillus paramycoides SP3 isolated from coal mine overburden leachate. EnvironPollut 2021, 285, 117519,https://doi.org/10.1016/j.envpol.2021.117519.

18. Sun, Y.; Shi, Y.; Jia, H.; Ding, H.; Yue, T.; Yuan, Y. Biosynthesis of selenium nanoparticles of Monascus purpureus and their inhibition to Alicyclobacillus acidoterrestris. Food Control2021, 130, 108366, https://doi.org/10.1016/j.foodcont.2021.108366.

19. Kora, A.J. Gram + ve bacterium Staphylococcus aureus: A potential source for the greenbiosynthesis of monodispersed, smaller selenium nanoparticles. Micro Nano Lett2018,13, 1155-1158, https://doi.org/10.1049/mnl.2017.0822.

20. Alam, H.; Khatoon, N.; Aasif, M.; Syed, K.; Husain, A. Synthesis of seleniumnanoparticles using probiotic bacteria Lactobacillus acidophilus and their enhancedantimicrobial activity against resistant bacteria. J Clust Sci2020, 31, 1003-1011,https://doi.org/10.1007/s10876-019-01705-6.

21. Saleh, J.; Edeas, M.; Van Goor, H. Antioxidant supplements and oxidative stress. Sultan Qaboos Univ Med J2019, 19, 177-180.

22. Menon, S.; Agarwal, H.; Rajeshkumar, S.; Jacquline Rosy, P.; Shanmugam, V.K. Investigating the antimicrobial activities of the biosynthesized selenium nanoparticles and its statistical analysis. Bionanoscience2020, 10, 122-135,https://doi.org/10.1007/s12668-019-00710-3.

23. Geoffrion, L.D.; Hesabizadeh, T.; Medina-Cruz, D.; Kusper, M.; Taylor, P.; Vernet-Crua, A.; Chen, J.; Ajo, A.; Webster, T.J.; Guisbiers, G. Naked selenium nanoparticles for antibacterial and anticancer treatments. ACS Omega2020, 5, 2660-2669, https://doi.org/10.1021/acsomega.9b03172.

24. Kumar, A.; Prasad, B.; Manjhi, J.; Prasad, K.S. Antioxidant activity of seleniumnanoparticles biosynthesized using a cell-free extract of Geobacillus. Toxicol Environ Chem2020, 102, 556-567, https://doi.org/10.1080/02772248.2020.1829623.

25. Yue, L.; Wang, D.; Liu, J. Biosynthesis of selenium nanoparticles, characterization andX-ray induced radiotherapy for the treatment of lung cancer with interstitial lungdisease. J Photochem Photobiol B Biol2019, 191, 123-127,https://doi.org/10.1016/j.jphotobiol.2018.12.008.

26. Khater, S.I.; Mohamed, A.A.-R.; Arisha, A.H.; Ebraheim, L.L.M.; El-Mandrawy, S.A.M.; Nassan, M.A.; Mohammed, A.T.; Abdo, S.A. Stabilized-chitosan selenium nanoparticles efficiently reduce renal tissue injury and regulate the expression pattern of aldose reductase in the diabetic-nephropathy rat model.Life Sci2021, 279, 119674, https://doi.org/10.1016/j.lfs.2021.119674.

27. Kanchi, S.; Inamuddin; Khan, A. Biogenic synthesis of selenium nanoparticles with edible mushroom extract: Evaluation of cytotoxicity on prostate cancer cell lines and their antioxidant, and antibacterial activity.Biointerface Res Appl Chem2020, 10, 6629-6639,https://doi.org/10.33263/briac106.66296639.

28. Baskar, G.; Lalitha, K.; George, G.B. Synthesis, characterization and anticancer activityof selenium nanobiocomposite of 1-asparaginase. Bull Mater Sci2019, 42, 1-7,https://doi.org/10.1007/s12034-018-1686Z.

29. Vahidi, H.; Barabadi, H. Emerging selenium nanoparticles to combat cancer : a systematic review. J Clust Sci2020, 31, 301-309,https://doi.org/10.1007/s10876-019-01671-z.

30. Cieśla, Ł.; Kryszeń, J.; Stochmal, A.; Oleszek, W.; Waksmundzka-Hajnos, M. Approachto develop a standardized TLC-DPPH test for assessing free radical scavengingproperties of selected phenolic compounds. J Pharm Biomed Anal2012, 70, 126-135,https://doi.org/10.1016/j.jpba.2012.06.007.

31. Benzie, I.F.F.; Strain, J.J. The ferric reducing ability of plasma (FRAP) as a measure of "antioxidant power": 
The FRAP Assay. Anal Biochem1996, 239, 70-76.

32. Ingole, A.R.; Thakare, S.R.; Khati, N.T.; Wankhade, A.V.; Burghate,D.K. Greensynthesis of selenium nanoparticles under ambient condition. Chalcogenide Lett2010,7, 485-489.

33. Prasad, K.S.; Selvaraj, K. Biogenic synthesis of selenium nanoparticles and their effecton As(III)- induced toxicity on human lymphocytes. Biol Trace Elem Res2014, 157,275-283, https://doi.org/10.1007/s12011014-9891-0.

34. Wang, T.; Yang, L.; Zhang, B.; Liu, J. Extracellular biosynthesis and transformation ofselenium nanoparticles and application in $\mathrm{H}_{2} \mathrm{O}_{2}$ biosensor. Colloids Surfaces B Biointerfaces2010, 80, 94-102, https://doi.org/10.1016/j.colsurfb.2010.05.041.

35. N. Srivastava, N.; Mukhopadhyay, M. Biosynthesis and structural characterization of selenium nanoparticles using Gliocladium roseum. J Clust Sci2015, 26, 1473-1482,https://doi.org/10.1007/s10876-014-0833-y.

36. Kamnev, A.A.; Mamchenkova, P.V.; Dyatlova, Y.A.; Tugarova, A.V. FTIRspectroscopic studies of selenite reduction by cells of the rhizobacterium Azospirillum brasilense $\mathrm{Sp} 7$ and the formation of selenium nanoparticles. J Mol Struct2017,1140,106-112, https://doi.org/10.1016/j.molstruc.2016.12.003.

37. Tugarova, A.V.; Mamchenkova, P.V.; Dyatlova, Y.A.; Kamnev, A.A. FTIR and Ramanspectroscopic studies of selenium nanoparticles synthesized by the bacteriumAzospirillum thiophilum. Spectrochim Acta Part A Mol Biomol Spectrosc2018, 192,458-463, https://doi.org/10.1016/j.saa.2017.11.050.

38. Lasch, P.; Naumann, D. Infrared spectroscopy in microbiology, in Encyclopedia of Analytical Chemistry, R.A. Meyers (Ed.) 2015, https://doi.org/10.1002/9780470027318.a0117.pub2.

39. Prasad, K.S.; Vaghasiya, J.V.; Soni, S.S.; Patel, J.; Patel, R.; Kumari, M.; Jasmani, F.;Selvaraj, K. Microbial selenium nanoparticles (SeNPs) and their application as asensitive hydrogen peroxide biosensor. Appl Biochem Biotechnol2015, 177,1386-1393, https://doi.org/10.1007/s12010-015-1814-9.

40. Cremonini, E.; Zonaro, E.; Donini, M.; Lampis, S.; Boaretti, M.; Dusi, S.; Melotti, P.;Lleo, M.M.; Vallini, G. Biogenic selenium nanoparticles: characterization, antimicrobial activity, and effects on human dendritic cells and fibroblasts. Microb Biotechnol2016, 9, 758-771, https://doi.org/10.1111/1751-7915.12374.

41. Mahmoodpoor, A.; Hamishehkar, H.; Shadvar, K.; Ostadi, Z.; Sanaie, S.; Saghaleini,S.H.; Nader, N.D. The effect of intravenous selenium on oxidative stress in criticallyill patients with acute respiratory distress syndrome. Immunol Invest2019, 48,147-159, https://doi.org/10.1080/08820139.2018.1496098.

42. Kong, H.; Yang, J.; Zhang, Y.; Fang, Y. Synthesis and antioxidant properties of gumarabic-stabilized selenium nanoparticles. Int J Biol Macromol2014, $\quad 65, \quad 155-$ 162,https://doi.org/10.1016/j.ijbiomac.2014.01.011.

43. Zhai, X.; Zhang, C.; Zhao, G.; Stoll, S.; Ren, F.; Leng, X. Antioxidant capacities of theselenium nanoparticles stabilized by chitosan. J Nanobiotechnology2017, 15, 1-12,https://doi.org/10.1186/s12951-016-0243-4. 